This item was submitted to Loughborough's Research Repository by the author.

Items in Figshare are protected by copyright, with all rights reserved, unless otherwise indicated.

\title{
Twisting techniques used in freestyle aerial skiing
}

PLEASE CITE THE PUBLISHED VERSION

http://journals.humankinetics.com/AcuCustom/SiteName/Documents/Documentltem/10727.pdf

PUBLISHER

(c) Human Kinetics

VERSION

AM (Accepted Manuscript)

LICENCE

CC BY-NC-ND 4.0

REPOSITORY RECORD

Yeadon, Maurice R.. 2019. "Twisting Techniques Used in Freestyle Aerial Skiing”. figshare. https://hdl.handle.net/2134/8685. 
This item was submitted to Loughborough's Institutional Repository (https://dspace.lboro.ac.uk/) by the author and is made available under the following Creative Commons Licence conditions.

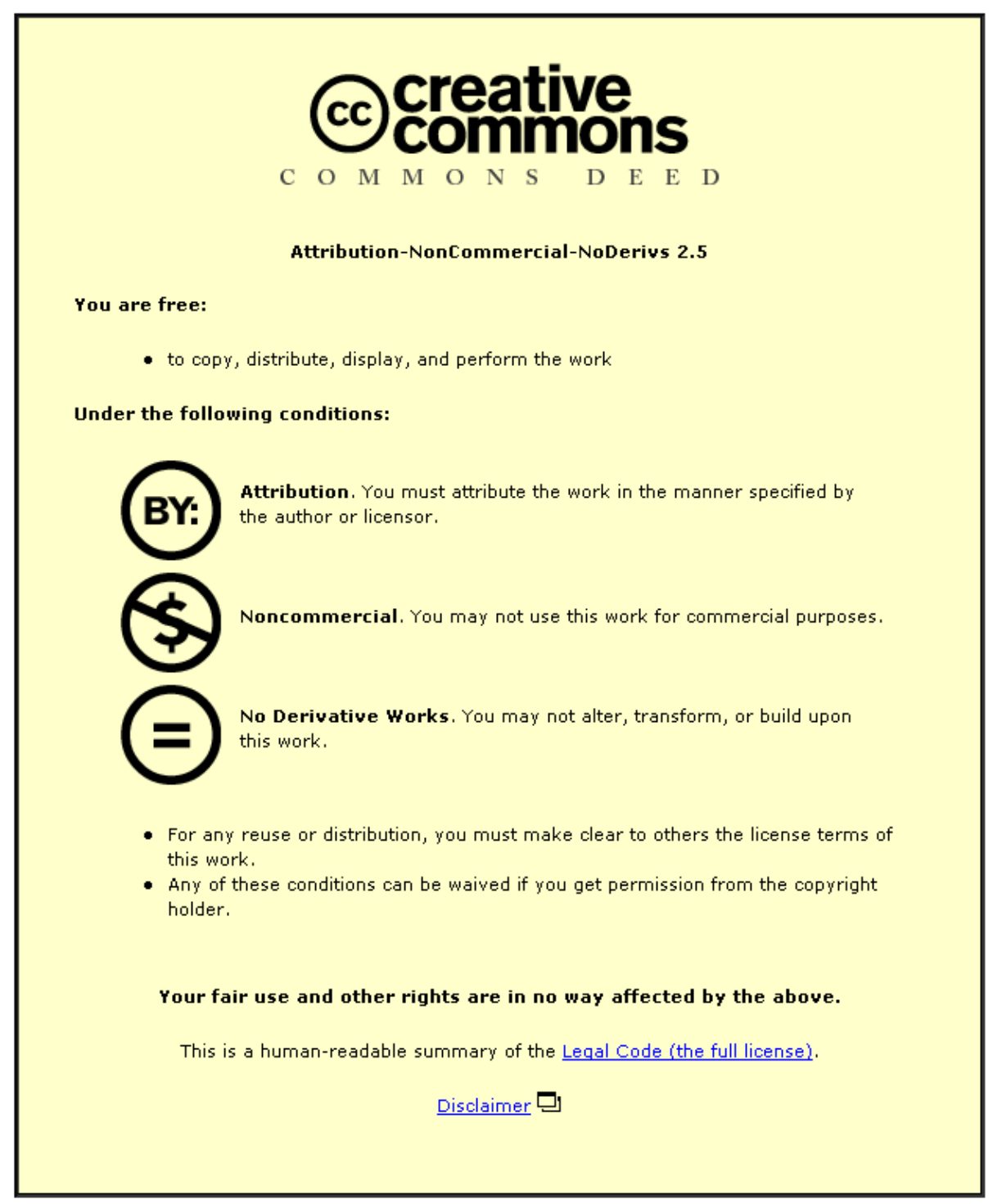

For the full text of this licence, please go to: http://creativecommons.org/licenses/by-nc-nd/2.5/ 


\title{
Twisting Techniques Used in Freestyle Aerial Skiing
}

\author{
Maurice R. Yeadon \\ Biomechanics Laboratory, University of Calgary, Calgary, Alberta, Canada T2N 1N4
}

\begin{abstract}
At the 1988 Calgary Winter Olympics, six triple somersaults with three twists or four twists were filmed using two cameras. Angles describing body configuration and orientation were determined and were used as input into a computer simulation model of aerial movement. It was found that the twist angle of each simulation deviated from the corresponding angle obtained from film by less than 0.08 revolutions during the first somersault of each movement. Contributions to the tilt angle after one somersault were determined using simulations based on modifications of the film data. It was found that of the six competitors, two initiated the twist during the takeoff phase, two initiated the twist during the aerial phase, and two used a combination of both methods.
\end{abstract}

Twisting somersaults comprise the main elements of tumbling, gymnastics dismounts, diving, trampolining, and freestyle aerial skiing. The aerials event in freestyle skiing exhibits the most complex movements of any of the related sports, showing two, three, and four twists during triple somersaults. Twisting techniques may be separated into those that start the twist during contact with the takeoff surface and those that initiate the twist during the aerial phase. The terms contact techniques and aerial techniques will be used in this paper.

Van Gheluwe (1981) used a 6-segment computer simulation model to analyze filmed performances of three full twisting backward somersaults from minitramp. It was found that aerial techniques were responsible for producing the twist. The aerial techniques were separated into asymmetrical movements of the arms and asymmetrical movements of the hips. It was found that most of the twist arose from asymmetrical arm movements.

Four performances of single and double somersaults with twist by an elite trampolinist were analyzed using an 11-segment simulation model (Yeadon, 1984). It was found that most of the twist resulted from aerial techniques, predominantly asymmetrical movements of the arms. It might be speculated that in general all twists are produced during the aerial phases using asymmetrical arm movements. It should be recognized, however, that in these studies by Van Gheluwe and Yeadon, only three elite athletes and seven skills were analyzed. It may be that different techniques are used in different sports. In the freestyle aerials event, the wearing of skis will change the segmental moments of inertia and this may be expected to influence both the skills performed and the techniques used. This study will determine the contributions made by contact and aerial twisting techniques to performances of triple somersaults with twist.

\section{Methods}

\section{Data Collection}

Prior to the freestyle aerials demonstration event at the 1988 Winter Olympics in Calgary, camera platforms $\mathrm{R}$ and $\mathrm{S}$ of heights $1.5 \mathrm{~m}$ and $3.5 \mathrm{~m}$ were erected to the rear and to the side of the takeoff kicker (Figure 1). These camera positions were located to the rear of the spectator area and were not ideal since their lines of sight made an angle of about $30^{\circ}$ rather than $90^{\circ}$, but they were considered adequate for obtaining three-dimensional information on the flight phases. A survey was conducted using a theodolite for direction measurements and an infrared electronic distance meter to obtain threedimensional coordinates of the corners of camera platforms $\mathrm{R}$ and $\mathrm{S}$, markers $\mathrm{M}$ and $\mathrm{P}$ attached to the takeoff kicker and a vertical pole, respectively, and a point $\mathrm{T}$ at the top of the inrun. These coordinates were to be used in the reconstruction of three-dimensional coordinates from digitized film data. 


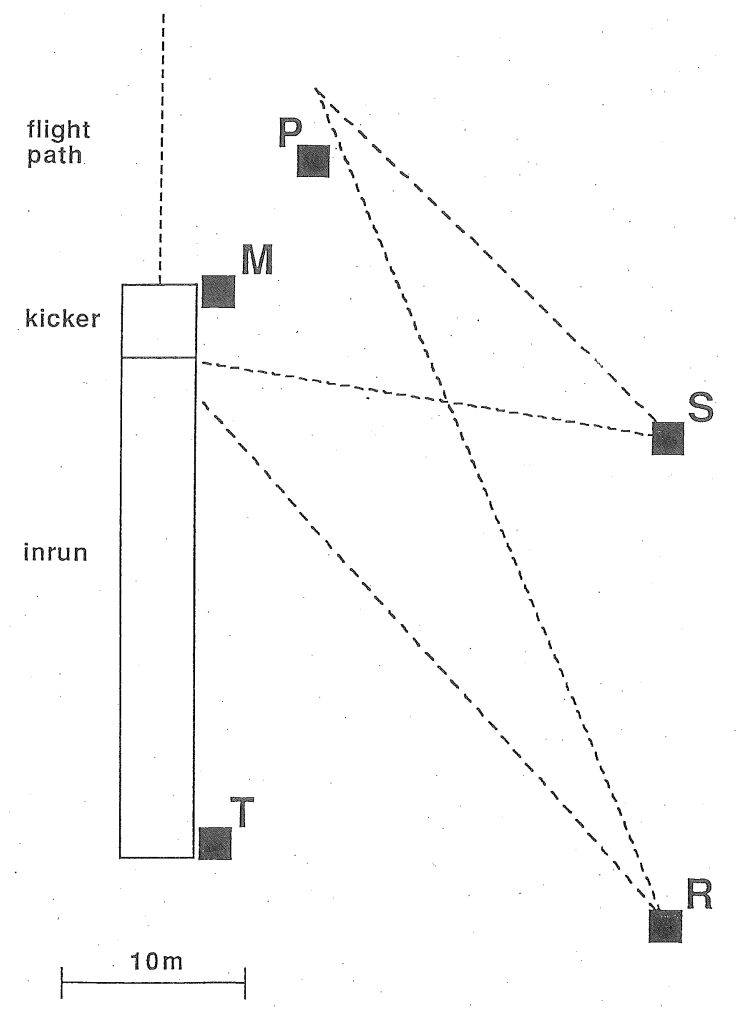

Figure 1: Locations of cameras $\mathrm{R}$ and $\mathrm{S}$ and markers $\mathrm{M}$ and $\mathrm{P}$.

One day prior to the competition, front and side views of 8 of the 14 competitors in the men's event were taken with a 16-mm cine camera so that segmental masses and moments of inertia could be calculated. A pair of freestyle skis were disassembled, weighed, and measured together with a pair of boots so that masses and moments of inertia could be calculated.

On the day of competition, the locations of camera lenses relative to the platforms were measured, zoom lenses were adjusted so that the fields of view included markers $\mathrm{M}$ and $\mathrm{P}$ and the flight phase of the jumpers, camera framing rates were set to $50 \mathrm{fps}$, and variable shutters were set to $1 / 3$. Light readings were taken from the landscape background, which was not snow covered, and camera apertures were adjusted throughout the event as the light faded. The camera platforms were linked by telephone so that direction could be given in the timing of camera operation, the identification of competitors, and the recording of the $\log$.

\section{Data Analysis}

Six performances of triple somersaults with three or four twists were selected for analysis. The corners of the film frame were each digitized four times and their mean coordinate values were taken to give the center of the image of the film frame. The images of the markers $\mathrm{M}$ and $\mathrm{P}$ were each digitized 16 times and average coordinate values were obtained for each marker. From the known three-dimensional locations of the rear camera, side camera, marker $\mathrm{M}$ and marker $\mathrm{P}$ and the digitized coordinates of the markers and the film frame center, a pseudo focal length in digitizer units was calculated together with pan and tilt angles giving the orientation of the camera's optical axis, and a screw angle giving the rotation about the axis. Details of the calculation of these camera parameters are given in Yeadon (1989) where the more general case of cameras with changing orientations is described.

In each film frame of the flight phase, 12 body landmarks were digitized: wrist, elbow, shoulder, hip, knee, and ankle centers. The head was assumed to be in normal alignment and the skis were assumed to be perpendicular to the lower legs. The latter assumption is reasonable since the skis are rigidly attached to the ski boots, which are not flexible. The film taken by each camera was digitized twice so that errors could be corrected and error estimates could be obtained for the fitting of quintic splines. 
The digitized data sets from the two cameras were synchronized by matching the paths traced by the center of mass of the body close to takeoff and to landing (Yeadon, 1989). The body was modeled using four arm segments, four leg segments, and three torso segments. The whole body orientation was defined by angles corresponding to somersault, tilt, and twist whereas body configuration was specified using 14 angles to describe the relative orientations of body segments. The three-dimensional coordinates of the digitized joint centers were reconstructed as described in Yeadon (1989), and the 17 orientation angles were calculated from the joint center locations using the method in Yeadon (1990a).

Anthropometric measurements were obtained by digitizing the front and side views of those competitors who were filmed prior to competition, and segmental masses, mass center locations, link lengths, and moments of inertia were determined (Yeadon, 1990b). For the other competitors, inertia values were taken from the athlete closest in height and weight. The disassembled freestyle skis were modeled as non-uniform rods with line density proportional to the cross-sectional area which was determined from width and depth measurements. The ski bindings were treated as point masses while the boots were of known mass with estimated center of mass locations and radii of gyration. The moment of inertia values of the lower legs were adjusted to account for the addition of boots and skis. No allowance was made for ski clothing.

An 11-segment model was used to determine the angular momentum vector during flight from a knowledge of the orientation angles and segmental inertias (Yeadon, 1990c). The mean values of the calculated angular momentum components and the time histories of the 14 configurational angles were input into an 11-segment simulation model (Yeadon, Atha, \& Hales, 1990). The values of the somersault, tilt, and twist angles determined by the simulation model were compared with the values obtained from the film data to evaluate the accuracy of the simulations.

The angle of tilt between the longitudinal axis of the body (corresponding to minimum moment of inertia) and the invariable plane perpendicular to the angular momentum vector is approximately proportional to the twist rate for a given body configuration (Yeadon, 1984). Thus the angle of tilt may be used as a measure of how much twist is present. The value of the tilt angle at takeoff is a measure of the contribution of twist initiation during contact with the takeoff kicker. The subsequent increase in the tilt angle during flight is a measure of the contribution of aerial twisting techniques to the observed tilt angle value. In order to subdivide the aerial contribution into contributions associated with asymmetries of arms, chest, and hips, the configurational angles obtained from film were modified. These modifications comprised the systematic removal of asymmetries of the arms, chest, and hips. The tilt angle produced after one somersault was determined from simulations based upon the modified configurations, and the contributions of arm, chest, and hip asymmetries to the tilt angle were calculated (Yeadon \& Dunn, 1987).

\section{Results and Discussion}

In each of the six twisting triples analyzed, the difference between the twist angle obtained from simulation and film was 0.08 revolutions or less during the first complete somersault and the first full twist. Table 1 presents the contributions made to the tilt angle at one somersault for each competitor. The term full-full-full refers to a triple somersault with one twist in each somersault. The term rudi means 1-1/2 twists, so a rudi-rudi-full is a triple somersault with 1-1/2 twists in each of the first two somersaults and a full twist in the third. The initial tilt angle is the angle between the longitudinal axis and the invariable plane at takeoff and is a measure of the contact twist generated during contact with the takeoff kicker. The symmetry contribution indicates how much the tilt angle increases from its initial value in a simulation that preserves symmetry of the arms, chest, and hips. It should be recognized that the tilt angle may be changed by raising or lowering both arms symmetrically at the quarter or three-quarter twist position. The contributions under arms, chest, and hips arise from asymmetrical arm movements, torsion of the chest, and lateral flexion at the hips. For each of the six twisting triples analyzed, the sum of the tilt contributions listed under total was within $1^{\circ}$ of the actual tilt obtained from the unmodified simulation. It should be noted that the values in Table 1 have been rounded to the nearest degree so that the value under the "total" heading is not always the sum of the stated individual values.

Of the six competitors, four had substantial initial tilt angles, showing that the twist had started during takeoff. Of these four, two competitors increased their tilt angles during flight while two did not. The remaining two competitors produced tilt in the aerial phase. Thus the six performances may be 
Table 1: Tilt Contributions for Six Twisting Triple Somersaults

\begin{tabular}{|c|c|c|c|c|c|c|c|}
\hline \multirow[b]{2}{*}{ Competitor } & \multirow[b]{2}{*}{ Movement } & \multicolumn{6}{|c|}{ Tilt contribution } \\
\hline & & Initial & Symmetry & Arms & Chest & Hips & Total \\
\hline$K F$ & full-full-full & 8 & -6 & 6 & -2 & 3 & 8 \\
\hline JB & full-full-full & 5 & 0 & 3 & 2 & -1 & 9 \\
\hline $\mathrm{TV}$ & full-full-full & 4 & -1 & 4 & -1 & 2 & 7 \\
\hline JR & full-full-full & 0 & 1 & 4 & 0 & 2 & 7 \\
\hline $\mathrm{DM}$ & full-rudi-rudi & -3 & 0 & 11 & -2 & 5 & 11 \\
\hline LL & rudi-rudi-full & 6 & -3 & 1 & 0 & 2 & 6 \\
\hline
\end{tabular}

categorized as two contact twisters, two aerial twisters, and two combination techniques. The major aerial technique used was asymmetrical arm movement. Asymmetrical hip movement made some contributions while chest torsion made little contribution. One reason for the small contributions made by the chest and hip asymmetries is that these two techniques are only effective when the body is flexed at the hips whereas these twisting triples are executed with the body extended. Figure 2 shows the full-full-full of J.R., who used aerial techniques; this may be compared with Figure 3 showing the rudi-rudi-full of L.L., who used contact techniques. The movements are viewed from the front, and the last half somersault of each movement is not shown.

This study has shown that elite athletes use various techniques for initiating twist in freestyle aerial somersaults. The particular technique used may have a bearing on the ease of landing a skill successfully. Those athletes employing aerial twist can stop the twist by removing the tilt prior to landing. On the other hand, the use of contact twist will tend to lead to a landing orientation that is tilted. Since the angles of tilt produced are not large, it is not obvious whether this will be a problem. The question of what techniques are used in preparation for landing will serve as a topic for future study.

\section{References}

Van Gheluwe, B. (1981). A biomechanical simulation model for airborne twist in backward somersaults. Journal of Human Movement Studies, 7, 1-22.

Yeadon, M.R. (1984). The mechanics of twisting somersaults. Doctoral dissertation. Loughborough University.

Yeadon, M.R. (1989). A method for obtaining three-dimensional data on ski jumping using pan and tilt cameras. International Journal of Sports Biomechanics, 5, 238-247. 


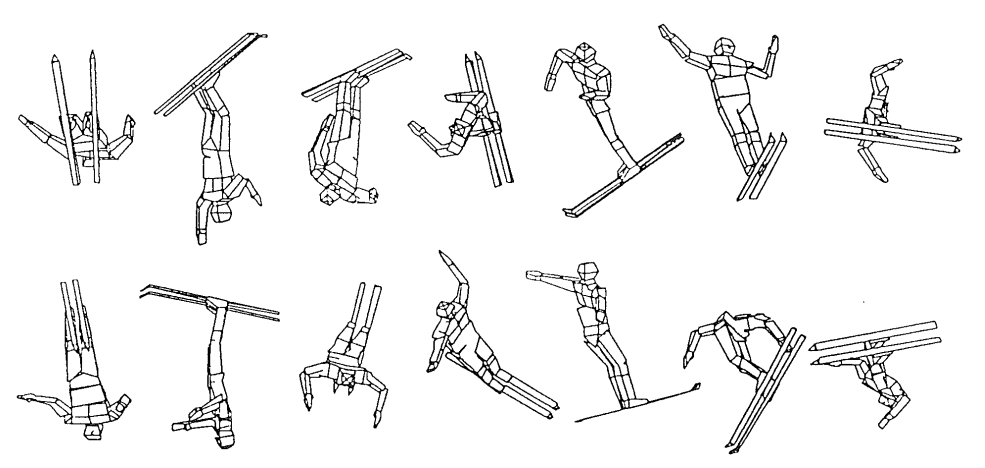

Figure 2: The full-full-full of J.R.

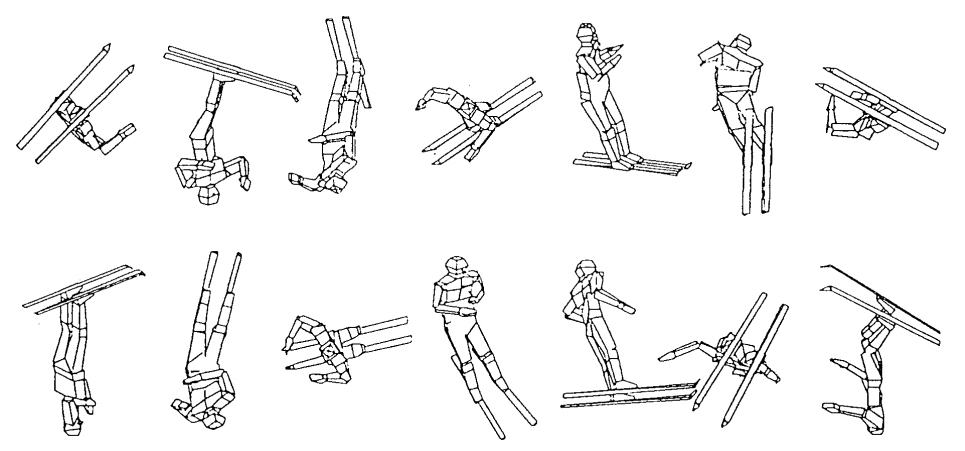

Figure 3: The rudi-rudi-full of L.L.

Yeadon, M.R. (1990a). The simulation of aerial movement - I: The determination of orientation angles from film data. Journal of Biomechanics, 23, 59-66.

Yeadon, M.R. (1990b). The simulation of aerial movement - II: A mathematical inertia model of the human body. Journal of Biomechanics, 23, 67-74.

Yeadon, M.R. (1990c). The simulation of aerial movement - III: The determination of the angular momentum of the human body. Joumal of Biomechanics, 23, 75-83.

Yeadon, M.R., Atha, J., \& Hales, F.D. (1990). The simulation of aerial movement - IV: A computer simulation model. Joumal of Biomechanics, 23, 85-89.

Yeadon, M.R., \& Dunn, E.G. (1987). A method for determining the contributions of aerial twisting techniques to performances of twisting somersaults. In Proceedings of the 11th Annual Meeting of the American Society of Biomechanics (pp. 161-162).

\section{Acknowledgments}

The support provided by the IOC Medical Commission and the Natural Sciences and Engineering Research Council, and the cooperation of the Intemational Ski Federation and CTV Television, are gratefully acknowledged. Additionally, this study was made possible through the support ofthe following sponsors: Red Lake Corporation, XV Olympic Winter Games Organizing Committee (OCO '88), and The University of Calgary. 